\title{
RELATION BETWEEN LEFT VENTRICULAR HYPERTROPHY AND SILENT ISCHEMIA DETECTED BY 24-HOUR HOLTER MONITOR IN HYPERTENSIVE AND TYPE 2 DIABETIC PATIENTS
}

\author{
By
Kareem El-Deen Ahmed Said, Mostafa Attia Al-Sawasany and Mohamed Samy Abd El-Samei \\ Department of Cardiology, Faculty of Medicine, Al-Azhar University, Cairo \\ Corresponding author: Kareem El-Deen Ahmed Said \\ Mobile: (+20)1000444350, E-mail: dr.kareeem1@gmail.com
}

\begin{abstract}
Background: Hypertension is a prevalent and well-recognized cardiovascular risk factor that predisposes to the development of left ventricular hypertrophy (LVH), coronary heart disease and systolic and diastolic dysfunction. The presence of high left ventricular (LV) mass or a high left ventricular mass index (LVMI) is reportedly an independent predictor of increased cardiovascular morbidity and mortality both in the general populations and in hypertensive populations. Ambulatory ECG (Holter) monitoring is a very effective way of measuring ischemic events over $24 \mathrm{hrs}$. period, it has advantages over exercise testing.
\end{abstract}

Objective: To assess presence of silent ischemia in type 2 diabetic and hypertensive patients with LVH in comparison to type 2 diabetic and hypertensive patients with normal LV geometry.

Patients and methods: This study was a pilot one that was carried out on 60 type 2 diabetic and hypertensive patients $(28$ males and 32 females aged $53.5 \pm 10.4)$. Thirty cases had LVH and the other 30 had normal geometry. This study was conducted from October 2018 to February 2020. All patients were subjected to complete history taking including comorbidities, risk factors and full clinical examination. Patients with baseline ST segment depression $>2 \mathrm{~mm}$ in 2 consecutive leads, mitral stenosis, aortic stenosis, congenital heart disease, atrial fibrillation, prior myocardial infarction (MI) or coronary artery bypass graft surgery $(\mathrm{CABG})$, pericardial diseases, advanced renal or hepatic disease were excluded. Echocardiography was done and LV assessment alongside with measuring LVMI. Also, all patients were investigated by 24 hours continuous holter monitoring, and all of them underwent further investigation to assess the presence of CAD either by coronary angiography or multislice CT coronary angiogram.

Results: There was a statistically significant relationship between the presence of LVH and positive Holter findings for silent ischemia.

Out of 30 patients with normal geometry, 25 patients $(83.3 \%)$ were negative and 5 patients $(16.7 \%)$ were positive for silent ischemia. Out of the other 30 patients with abnormal geometry (LVH), 9 patients (30\%) were negative and 21 patients $(70 \%)$ were positive for silent ischemia. In 10 patients with mild LVH, 4 patients $(40 \%)$ were negative and 6 patients $(60 \%)$ were positive for silent ischemia. Out of 14 patients with moderate $\mathrm{LVH}, 4$ patients (28.6\%) were negative and 10 patients $(71.4 \%)$ were positive for silent ischemia. As regards the last 6 patients with severe LVH, 1 patient (16.7\%) was negative and 5 patients (83.3\%) were positive for silent ischemia.

Conclusion: The prevalence of silent ischemia markedly increased amongst diabetic and hypertensive patients with LVH in comparison to those with normal left ventricular geometry. The incidence of silent 
ischemia increased with increased LVMI. Ambulatory ECG monitoring may have a use in the identification of those at greatest risk of cardiovascular complications and sudden death.

Keywords: Hypertension, diabetes mellitus, silent ischemia, echocardiography, left ventricular mass index, 24 hrs. continuous holter monitoring.

\section{INTRODUCTION}

Hypertension is an established risk factor for atherosclerotic CAD and cerebrovascular disease (Rosendorff et al., 2015).

HHD is the heart's response to sustained arterial hypertension. It is initially a functionally adaptive process in response to increased left ventricular (LV) afterload. The hallmarks of this process are the development of $\mathrm{LVH}$, myocardial ischemia, diastolic dysfunction, myocardial fibrosis, apoptosis, cardiomyocyte growth, endothelial dysfunction, and increased arterial stiffness (Diez et al., 2010).

Left ventricular hypertrophy (LVH) has been long recognized as an independent risk factor for cardiovascular morbidity and mortality, including sudden cardiac death and dysrhythmia, heart failure, ventricular ischemia, and coronary heart disease (Diez et al., 2010 and Frohlich et al., 2011).

Traditionally, cardiomyocytes were thought to be postmitotic, with the heart unable to regenerate cardiomyocytes after cell death (e.g., post myocardial infarction). Contemporary evidence suggests, however, that cardiac cells, both cardiomyocytes and interstitial cells, are continually replaced by newer cell populations. It is likely, therefore, that LVH results from a combination of both extracellular fibrosis and hypertrophy $(\mathrm{Du}$ et al., 2010).
As LV mass increases, there is increased oxygen demand. Cardiomyocytes hypertrophy to compensate for this. There is no corresponding increase, in capillary numbers with a resultant mismatch between capillary and myocyte numbers. Thus, as oxygen demand increases, perfusion is unable to compensate accordingly. This phenomenon is termed, coronary microvascular dysfunction. Commonly, this causes no problems at rest with decompensation occurring only when the myocardium is placed under stress (e.g., exercise or pharmacologic agents). This explains the high prevalence of myocardial ischemia seen in hypertensive patients with non-obstructive CAD (Sara et al., 2015) and the subsequent elevated risk of major adverse cardiac events and all-cause mortality (Jespersen et al., 2012).

Coronary artery disease (CAD) is the major cause of morbidity and mortality in patients with diabetes. It is usually more advanced at the time of diagnosis and has unfavorable prognosis in diabetic patients.

Silent myocardial ischemia (SMI) is a common manifestation of coronary artery disease (CAD). It is typically defined as the presence of objective evidence of myocardial ischemia in the absence of chest discomfort or other anginal equivalents. Most silent ischemic episodes occur during minimal or no physical exertion. 
The exact reasons for the development of angina during some episodes of myocardial ischemia and the absence of symptoms during other episodes are not known. Some mechanisms include inability to reach pain threshold during an episode of ischemia, lesser severity and shorter duration of ischemic episodes, presence of higher threshold for pain, generalized defective perception of painful stimuli and presence of a defective anginal warning system.

SMI is associated with an increase in coronary risk that may be reversible with appropriate therapy. The risk of silent ischemia is increased substantially in patients with diabetes, particularly if they have other risk factors. Exercise treadmill test (ETT) and ambulatory (Holter) monitoring are the most readily available and frequently used tests to identify silent ischemia in clinical practice. Therapy for asymptomatic episode is equal as for the symptomatic one (Boras et al., 2010).

The aim of this study was to assess presence of silent ischemia in type 2 diabetic and hypertensive patients with LVH in comparison to type 2 diabetic and hypertensive patients with normal LV geometry.

\section{PATIENTS AND METHODS}

This study was a pilot one that was carried out on 60 type 2 diabetic and hypertensive patients presented to echocardiography unit. Thirty patients were with LVH according to American Society of Echocardiography (ASE), and 30 patients were with normal LV geometry according to American Society of Echocardiography (ASE) (Lang et al., 2015).
This study was conducted at the department of cardiology, Sharq Elmadina hospital from October 2018 to February 2020.

Complete history was taken and complete physical examination included both general ad local examination was done.

All patients did a transthoracic echocardiography and were investigated by a 24 hrs. Holter monitoring Electrocardiography (cECG), and all patients with positive holter finding underwent further investigation to assess the presence of CAD either by coronary angiography or multislice CT coronary angiogram.

\section{Exclusion criteria:}

- Baseline ST segment depression > 2 $\mathrm{mm}$ in 2 consecutive leads.

- Mitral stenosis, aortic stenosis and congenital heart disease.

- Atrial fibrillation.

- Prior myocardial infarction (MI) or Coronary Artery Bypass Graft surgery (CABG), because the formulae used for LVMI or RWT evaluation could not be applied due to the lack of homogeneity of wall thickness (e.g., scarring).

- Pericardial diseases.

- Advanced renal or hepatic disease.

An approval of the study was obtained from Al- Azhar University Academic and Ethical Committee. Every patient signed an informed written consent for participation in the study.

Transthoracic echocardiography was performed to all patients using Philips HD $11 \mathrm{XE}$ ultrasound, equipped with $4 \mathrm{MHz}$ 
transducer. Images were obtained while the patient in the left lateral decubitus position. ECG was connected to define timing of cardiac cycle events. All patients were subjected to detailed $\mathrm{M}$ mode, conventional two dimensional, and Doppler echocardiographic examinations using standard parasternal and apical views following the recommendations of the American Society of Echocardiography (ASE) (Lang et al., 2015).

All measurements were taken on three consecutive beats and the mean values were used. No measurements were taken within five cycles of an ectopic beat.

\section{The following parameters were measured:}

1. Left ventricular dimensions were taken at end diastole (at the onset of the $\mathrm{R}$ wave). Parasternal long axis view (PLAX) with M-Mode curser aligned perpendicular over the septum and posterior wall through mid-ventricular cavity:

- Left ventricular end-diastolic diameter (LVEDD).

- Left ventricular end-systolic diameter (LVESD).

End-diastolic and end-systolic diameters were defined as the measurement from the true endocardial border of the septum to the true endocardial border of the posterior wall.

- Septal wall thickness (SWT) in both diastole (SWTd) and systole (SWTs).
- Posterior wall thickness (PWT) in both diastole (PWTd) and systole (PWTs).

2. Left ventricular $\mathrm{EF} \%$ by measuring end diastolic diameter and end systolic diameter ejection fraction (EF) calculated as following:

$\mathrm{EF}=$ LVEDD3 - LVESD3/ LVEDD3

LV systolic dysfunction was defined as LVEF $<52 \%$ for men and $<54 \%$ for women (Lang et al., 2015).

3. Left ventricular mass index (LVMI) was determined using the following equation (Devereux et al., 2013):

LV mass $=0.8(1.04$ [LVID+ PWTd+ SWTd $] 3-[$ LVID] 3$)+0.6 \mathrm{~g}$.

LVMI=LVM/body surface area.

4. Relative wall thickness (RWT) was calculated by dividing the sum of SWTd and PWTd by the LVEDD.

RWT of 0.22 to 0.42 was regarded as normal (Lang et al., 2015).

The reference ranges used to define abnormal left ventricular thickness were (Lang et al., 2015):

RWT (male and female)> 0.42 .

LVMI (male) $>115 \mathrm{~g} / \mathrm{m} 2$.

LVMI (female) $>95 \mathrm{~g} / \mathrm{m} 2$.

Classification of $\mathrm{LVH}$ was according to $L$ VMI values (Lang et al., 2005):

1. Mild LVH in males (116-131 g/m2), and in females (96-108 g/m2).

2. Moderate LVH in males (132-148 $\mathrm{g} / \mathrm{m} 2)$, and in females (109-121 g/m2).

3. Severe LVH in males $(\geq 149 \mathrm{~g} / \mathrm{m} 2)$, and in females $(\geq 122 \mathrm{~g} / \mathrm{m} 2)$. 
Four LV geometric patterns were identified on the basis of LV mass index and RWT (Hashem et al., 2015):

- Normal (normal LV mass index, normal RWT).

- Concentric remodeling (normal LV mass index, abnormal RWT).

- Eccentric hypertrophy (abnormal LV mass index, normal RWT).

- Concentric hypertrophy (abnormal LV mass index, abnormal RWT).

\section{A 24 hrs. Holter monitoring Electrocardiography (ECG):}

All 60 patients underwent 24-h cECG monitoring and were attached to the DMS 300-3A Holter recorder.

All patients were instructed to engage in routine daily activity and to push a marker button whenever they feel any attack of chest pain. The data were analyzed by the DM software Cardio Scan II for assessment of the following:

1. Minimal, average and maximum heart rate.

2. Presence of transient ischemic events detected by transient ST depression $>1$ $\mathrm{mV}(1 \mathrm{~mm})$ lasted for $>1 \mathrm{~min}$ (Smith et al., 2000).

3. Assessment of presence of arrythmias and arrythmias related to the silent ischemia as ventricular tachycardia (VT), couplets and frequent premature ventricular contractions (PVCs).
A transient ischemic event during the cECG as detected if a horizontal or descending ST segment depression occurs with the measure of at least $1 \mathrm{~mm}$ and lasts for at least 1 minute. The ischemic event begins when the ST deviation reach $1 \mathrm{~mm}$ and considered finished when the value falls below $1 \mathrm{~mm}$ (Smith et al., 2000).

All patients with positive holter finding underwent further investigation to assess the presence of CAD either by coronary angiography or multislice CT coronary angiogram.

\section{Statistical methods:}

Recorded data were analyzed using the statistical package for social sciences, version 20.0 (SPSS Inc., Chicago, Illinois, USA). Quantitative data were expressed as mean \pm standard deviation (SD). Qualitative data were expressed as frequency and percentage.

- Independent-samples t-test of significance was used when comparing between two means.

- Chi-square (x2) test of significance was used in order to compare proportions between qualitative parameters.

- P-value $\leq 0.05$ was considered significant. 


\section{RESULTS}

Out of the 60 patients, 30 patients (50\%) had normal geometry, and the other 30 had abnormal geometry (LVH). The distribution of the LVH patients was as follow: 10 patients with mild concentric LVH (16.7\%), 14 patients with moderate concentric LVH (23.3\%) and 6 patients with severe concentric LVH (10\%).

By Holter finding, 34 patients $(56.66 \%)$ were negative for silent ischemia, and 26 patients $(43.34 \%)$ were positive for silent ischemia. The mean age was $53.5 \pm 10.4$ years (Mean $\pm \mathrm{SD}$ ) (Range: $34-76$ years), $10 \%$ were $<40$ years (6 patients), $28.3 \%$ (17 patients) were $40-<50$ years, $30 \%$ were $50-<60$ (18 patients), whereas $31.7 \% \geq 60$ years (19 patients). The sex distribution was 28 males (46.7\%) and 32 females (53.3\%). (Table 1).

Table (1): Distribution of the studied cases $(n=60)$

\begin{tabular}{|l|c|c|}
\hline Cases & No. & $\%$ \\
Parameters & 30 & 50.0 \\
\hline Normal geometry & 30 & 50.0 \\
Abnormal geometry & 10 & 16.7 \\
Mild concentric hypertrophy & 14 & 23.3 \\
$\quad$ Moderate concentric hypertrophy & 6 & 10.0 \\
$\quad$ Sever concentric hypertrophy & 34 & 56.7 \\
\hline Holter findings & 26 & 43.3 \\
$\quad$ Negative for silent ischemia & 28 & 46.7 \\
$\quad$ Positive for silent ischemia & 32 & 53.3 \\
\hline Sex & \multicolumn{2}{|c|}{} \\
\hline Male & 6 & 10.0 \\
\hline Female & 17 & 28.3 \\
\hline Age (years) & 18 & 30.0 \\
\hline$<40$ & 19 & 31.7 \\
\hline $40-<50$ & \multicolumn{2}{|c|}{$34.0-76.0$} \\
\hline $50-<60$ & $54.0(44.25-61.75)$ \\
\hline$\geq 60$ &
\end{tabular}

As regards age, 30 patients had normal geometry in whom the mean age was $55 \pm$ 10.5 years (Mean \pm SD) (Range: $35-76$ years), where 2 patients of them were $<40$ years $(6.7 \%), 7$ patients were $40-<50$ years $(23.3 \%), 10$ patients were $50<60$ years $(33.3 \%)$ and 11 patients were $\geq 60$ years $(36.7 \%)$ (Table 2).

The other 30 patients had abnormal geometry, 10 patients had mild LVH in whom the mean age was $50 \pm 11.2$ years (Mean \pm SD) (Range: 34 - 66 years), where 2 patients of them were $<40$ years $(20 \%)$, 3 patients were $40-<50$ years
$(30 \%)$, 3 patients were $50<60$ years $(30 \%)$ and 2 patients were $\geq 60$ years (20\%) (Table 2).

Fourteen patients were with moderate $\mathrm{LVH}$ as the mean age was $51.3 \pm 8.9$ years (Mean \pm SD) (Range: $39-67$ years), 1 patient of them was $<40$ years $(7.1 \%), 6$ patients were $40-<50$ years $(42.9 \%), 4$ patients were $50-<60$ years $(28.6 \%)$ and 3 patients were $\geq 60$ years (21.4\%) (Table 2).

In the last 6 patients with severe $\mathrm{LVH}$, the mean age was $56.5 \pm 11.6$ years (Mean \pm SD) (Range: $37-69$ years). Out of 6 
patients, 1 patient was <40 years $(16.7 \%)$, 1 patient was $40-<50$ years $(16.7 \%), 1$ patient was $50-<60$ years $(16.7 \%)$ and 3 patients were $\geq 60$ years $(50 \%)$ (Table 2 ).

Table (2): Relation between $\mathrm{LV}$ geometry and age (years)

\begin{tabular}{|c|c|c|c|c|c|c|c|c|c|}
\hline \multirow{2}{*}{ Age (years) } & \multicolumn{2}{|c|}{$\begin{array}{l}\text { Normal } \\
(\mathbf{n}=\mathbf{3 0})\end{array}$} & \multicolumn{2}{|c|}{$\begin{array}{l}\text { Mild } \\
(n=10)\end{array}$} & \multicolumn{2}{|c|}{$\begin{array}{l}\text { Moderate } \\
(n=14)\end{array}$} & \multicolumn{2}{|c|}{$\begin{array}{l}\text { Severe } \\
(n=6)\end{array}$} & \multirow[b]{2}{*}{$\mathbf{p}$} \\
\hline & No. & $\%$ & $\begin{array}{l}\mathbf{N} \\
\text { o. }\end{array}$ & $\%$ & $\begin{array}{l}\mathbf{N} \\
\text { o. }\end{array}$ & $\%$ & $\begin{array}{l}\text { N } \\
\text { o. }\end{array}$ & $\%$ & \\
\hline$<40$ & 2 & 6.7 & 2 & $\begin{array}{l}20 . \\
0\end{array}$ & 1 & 7.1 & 1 & $\begin{array}{l}16 . \\
7\end{array}$ & \multirow{4}{*}{$p=0.775$} \\
\hline $40-<50$ & 7 & $\begin{array}{l}23 . \\
3\end{array}$ & 3 & $\begin{array}{l}30 . \\
0\end{array}$ & 6 & $\begin{array}{l}42 . \\
9\end{array}$ & 1 & $\begin{array}{l}16 . \\
7\end{array}$ & \\
\hline $50-<60$ & 10 & $\begin{array}{l}33 . \\
3\end{array}$ & 3 & $\begin{array}{l}30 . \\
0\end{array}$ & 4 & $\begin{array}{l}28 . \\
6\end{array}$ & 1 & $\begin{array}{l}16 . \\
7\end{array}$ & \\
\hline$\geq 60$ & 11 & $\begin{array}{l}36 . \\
7\end{array}$ & 2 & $\begin{array}{l}20 . \\
0\end{array}$ & 3 & $\begin{array}{l}21 . \\
4\end{array}$ & 3 & 50 & \\
\hline Min. - Max. & \multicolumn{2}{|c|}{$35-76$} & \multicolumn{2}{|c|}{$34-66$} & \multicolumn{2}{|c|}{$39-67$} & \multicolumn{2}{|c|}{$37-69$} & \multirow{3}{*}{0.414} \\
\hline Mean \pm SD & \multicolumn{2}{|c|}{$55.0 \pm 10.5$} & \multicolumn{2}{|c|}{$50 \pm 11.2$} & \multicolumn{2}{|c|}{$51.3 \pm 8.9$} & \multicolumn{2}{|c|}{$\begin{array}{l}56.5 \\
11.6\end{array}$} & \\
\hline Median (IQR) & \multicolumn{2}{|c|}{$\begin{array}{l}55.5 \\
(45.7-61.3)\end{array}$} & \multicolumn{2}{|c|}{$\begin{array}{l}49 \\
(41 \\
60.5)\end{array}$} & \multicolumn{2}{|c|}{$\begin{array}{l}50 \\
(45 \\
57.3)\end{array}$} & \multicolumn{2}{|c|}{$\begin{array}{l}60 \\
(46- \\
65.3)\end{array}$} & \\
\hline
\end{tabular}

$\mathrm{p}$ : $\mathrm{p}$ value for comparing between the studied groups

There was a statistically significant relationship between the presence of $\mathrm{LVH}$ and positive holter findings for silent ischemia $(\mathrm{p}=<0.001)$. Out of 30 patients with normal geometry, 25 patients $(83.3 \%)$ were negative for silent ischemia and 5 patients $(16.7 \%)$ were positive for silent ischemia. Out of the other 30 patients with abnormal geometry $(\mathrm{LVH}) 9$ patients $(30 \%)$ were negative for silent ischemia and 21 patients $(70 \%)$ were positive for silent ischemia (Table 3).
In 10 patients with mild $\mathrm{LVH}, 4$ patients (40\%) were negative for silent ischemia and 6 patients $(60 \%)$ were positive for silent ischemia, whereas, out of 14 patients with moderate LVH, 4 patients $(28.6 \%)$ were negative for silent ischemia and 10 patients $(71.4 \%)$ were positive for silent ischemia (Table 3).

The last 6 patients with severe LVH, 1 patient $(16.7 \%)$ was negative for silent ischemia and 5 patients $(83.3 \%)$ were positive for silent ischemia (Table 3).

Table (3): Relation between LV geometry and holter finding

\begin{tabular}{|c|c|c|c|c|c|c|c|c|c|c|}
\hline LV geometry & & $\begin{array}{l}\text { mal } \\
\text { 30) }\end{array}$ & $\begin{array}{l}\text { Mild } \\
\text { (n }\end{array}$ & $\begin{array}{l}\text { VH } \\
\text { 10) }\end{array}$ & $\begin{array}{r}\text { Mod } \\
\text { L } \\
(\mathbf{n}=\end{array}$ & $\begin{array}{l}\text { rate } \\
\text { H } \\
\text { 14) }\end{array}$ & & & $c^{2}$ & p \\
\hline Holter findings & No. & $\%$ & No. & $\%$ & No. & $\%$ & No. & $\%$ & & \\
\hline $\begin{array}{l}\text { Negative for Silent } \\
\text { Ischemia }\end{array}$ & 25 & 83.3 & 4 & 40.0 & 4 & 28.6 & 1 & 16.7 & $10401 *$ & 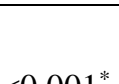 \\
\hline $\begin{array}{l}\text { Positive for Silent } \\
\text { Ischemia }\end{array}$ & 5 & 16.7 & 6 & 60.0 & 10 & 71.4 & 5 & 83.3 & 18.401 & $<0.001$ \\
\hline
\end{tabular}

$\chi 2$ : Chi square test,

$\mathrm{p}$ : $\mathrm{p}$ value for comparing between the studied groups 
Out of the 60 patients included in our study, 27 patients $(45 \%)$ had coronary artery disease. whereas, 33 patients $(55 \%)$ had normal coronary angiography (Table 4).

Table (4): Distribution of the studied cases according to CAD presence $(n=60)$

\begin{tabular}{|l|c|c|}
\hline CAD presence & No. & \% \\
\hline No & 33 & 55 \\
\hline Yes & 27 & 45 \\
\hline
\end{tabular}

Out of the 60 studied patients, 33 patients of them did not have CAD, 24 patients were negative for silent ischemia by holter $(72.7 \%)$, and 9 patients were positive for silent ischemia by holter $(27.3 \%)$. The specificity of holter finding to predict the presence CAD was $(72.73 \%)$. The other 27 patients who proved to have CAD, 10 of them were negative for silent ischemia by holter (37\%), and 17 patients were positive for silent ischemia by holter $(63 \%)$. The sensitivity of holter finding to predict the presence CAD was (62.96\%) (Table 5).

Out of the 30 patients with normal geometry, 21 patients of them did not have CAD, 19 patients were negative for silent ischemia by holter $(90.5 \%)$, and 2 patients were positive for silent ischemia by holter $(9.5 \%)$. The specificity of holter finding to predict the presence CAD was $(97.3 \%)$. The other 9 patients who proved to have CAD, 6 of them were negative for silent ischemia by holter $(66.7 \%)$, and 3 patients were positive for silent ischemia by holter $(33.3 \%)$. The sensitivity of holter finding to predict the presence of CAD was (33.33\%) (Table 5).

Out of the 30 patients with LVH, 12 patients of them did not have CAD, 5 patients were negative for silent ischemia by holter $(41.7 \%)$, and 7 patients were positive for silent ischemia by holter $(58.3 \%)$. The specificity of holter finding to predict the presence of CAD was (41.67\%). The other 18 patients who proved to have CAD, 4 of them were negative for silent ischemia by holter
(22.2\%), and 14 patients were positive for silent ischemia by holter $(77.8 \%)$. The sensitivity of holter finding to predict the presence of CAD was (80.95\%) (Table 5).

Out of the 10 patients with mild concentric LVH, 5 patients of them did not have $\mathrm{CAD}, 3$ patients were negative for silent ischemia by holter $(60 \%)$, and 2 patients were positive for silent ischemia by holter $(40 \%)$. The specificity of holter finding to predict the presence of CAD was $(60 \%)$. The other 5 patients who proved to have CAD, 1 of them was negative for silent ischemia by holter (20\%), and 4 patients were positive for silent ischemia by holter $(80 \%)$. The sensitivity of holter finding to predict the presence of CAD was (80\%) (Table 5).

Out of the 14 patients with moderate concentric LVH, 6 patients of them did not have CAD, 2 patients were negative for silent ischemia by holter $(33.3 \%)$, and 4 patients were positive for silent ischemia by holter $(66.7 \%)$. The specificity of holter finding to predict the presence of CAD was $(33.3 \%)$. The other 8 patients who proved to have CAD, 2 of them were negative for silent ischemia by holter $(25 \%)$, and 6 patients were positive for silent ischemia by holter $(75 \%)$. The sensitivity of holter finding to predict the presence of CAD was (75\%) (Table 5).

Out of the last 6 patients with severe concentric LVH, 1 patient of them did not have $\mathrm{CAD}$, and he was positive for silent ischemia by holter. The specificity of holter finding to predict the presence of CAD was $(0 \%)$. The other 5 patients who 
proved to have CAD, 1 of them was negative for silent ischemia by holter (20\%), and 4 patients were positive for silent ischemia by holter $(80 \%)$. The sensitivity of holter finding to predict the presence of CAD was (80\%) (Table 5).

Table (5): Sensitivity, specificity and accuracy for Holter finding

\begin{tabular}{|c|c|c|c|c|c|c|c|c|c|}
\hline \multirow{2}{*}{$\begin{array}{l}\text { CAD presence } \\
\text { Holter findings }\end{array}$} & \multicolumn{2}{|c|}{ No } & \multicolumn{2}{|c|}{ Yes } & \multirow{2}{*}{ 昰 } & \multirow{2}{*}{ 营 } & \multirow[b]{2}{*}{ a } & \multirow[b]{2}{*}{$\frac{1}{z}$} & \multirow{2}{*}{ 冚 } \\
\hline & No. & $\%$ & No. & $\%$ & & & & & \\
\hline Total sample $(n=60)$ & \multicolumn{2}{|c|}{$(n=33)$} & \multicolumn{2}{|c|}{$(n=27)$} & & & & & \\
\hline $\begin{array}{l}\text { Negative for Silent } \\
\text { Ischemia }\end{array}$ & 24 & 72.7 & 10 & 37.0 & \multirow{2}{*}{62.96} & \multirow{2}{*}{72.73} & \multirow{2}{*}{65.38} & \multirow{2}{*}{70.59} & \multirow{2}{*}{68.33} \\
\hline $\begin{array}{l}\text { Positive for Silent } \\
\text { Ischemia }\end{array}$ & 9 & 27.3 & 17 & 63.0 & & & & & \\
\hline $\begin{array}{l}\text { Normal geometry (n } \\
=30)\end{array}$ & \multicolumn{2}{|c|}{$(\mathrm{n}=21)$} & \multicolumn{2}{|c|}{$(\mathrm{n}=9)$} & & & & & \\
\hline $\begin{array}{l}\text { Negative for Silent } \\
\text { Ischemia }\end{array}$ & 19 & 90.5 & 6 & 66.7 & \multirow{2}{*}{33.33} & \multirow{2}{*}{97.53} & \multirow{2}{*}{60.0} & \multirow{2}{*}{92.94} & \multirow{2}{*}{91.11} \\
\hline $\begin{array}{l}\text { Positive for Silent } \\
\text { Ischemia }\end{array}$ & 2 & 9.5 & 3 & 33.3 & & & & & \\
\hline $\begin{array}{l}\text { Mild Concentric } \\
\text { Hypertrophy }(n=10)\end{array}$ & \multicolumn{2}{|c|}{$(\mathrm{n}=5)$} & \multicolumn{2}{|c|}{$(n=5)$} & & & & & \\
\hline $\begin{array}{l}\text { Negative for Silent } \\
\text { Ischemia }\end{array}$ & 3 & 60.0 & 1 & 20.0 & \multirow{2}{*}{80.0} & \multirow{2}{*}{60.0} & \multirow{2}{*}{66.67} & \multirow{2}{*}{75.0} & \multirow{2}{*}{70.0} \\
\hline $\begin{array}{l}\text { Positive for Silent } \\
\text { Ischemia }\end{array}$ & 2 & 40.0 & 4 & 80.0 & & & & & \\
\hline $\begin{array}{l}\text { Moderate Concentric } \\
\text { Hypertrophy }(n=14)\end{array}$ & \multicolumn{2}{|c|}{$(n=6)$} & \multicolumn{2}{|c|}{$(\mathrm{n}=8)$} & & & & & \\
\hline $\begin{array}{l}\text { Negative for Silent } \\
\text { Ischemia }\end{array}$ & 2 & 33.3 & 2 & 25.0 & \multirow{2}{*}{75.0} & \multirow{2}{*}{33.3} & \multirow{2}{*}{60.0} & $50 \Omega$ & \\
\hline $\begin{array}{l}\text { Positive for Silent } \\
\text { Ischemia }\end{array}$ & 4 & 66.7 & 6 & 75.0 & & & & 50.0 & $5 \% .14$ \\
\hline $\begin{array}{l}\text { Severe Concentric } \\
\text { Hypertrophy }(n=6)\end{array}$ & & & & & & & & & \\
\hline $\begin{array}{l}\text { Negative for Silent } \\
\text { Ischemia }\end{array}$ & 0 & 0.0 & 1 & 20.0 & 800 & O & OPO & O & \\
\hline $\begin{array}{l}\text { Positive for Silent } \\
\text { Ischemia }\end{array}$ & 1 & 100 & 4 & 80.0 & 80.0 & 0.0 & 80.0 & 0.0 & $00.0 /$ \\
\hline $\begin{array}{l}\text { Total } L V H \text { cases }(n= \\
\text { 30) }\end{array}$ & $(\mathrm{n}$ & 12) & & 18) & & & & & \\
\hline $\begin{array}{l}\text { Negative for Silent } \\
\text { Ischemia }\end{array}$ & 5 & 41.7 & 4 & 22.2 & & & & & \\
\hline $\begin{array}{l}\text { Positive for Silent } \\
\text { Ischemia }\end{array}$ & 7 & 58.3 & 14 & 77.8 & 80.95 & 41.67 & 70.83 & 55.56 & 66.67 \\
\hline
\end{tabular}

\section{DISCUSSION}

Hypertensive heart disease (HHD) is defined as the response of the heart to the afterload applied on the left ventricle by the progressively increasing arterial pressure and total peripheral resistance (Garg et al., 2017).

HHD is characterized by increased left ventricular (LV) mass associated with left ventricular hypertrophy (LVH). Hypertension-induced LVH is a result of a 
sum of genetic, functional, and structural abnormalities of cardiac tissue that lead to its differentiation as a separate entity, which is referred to as a so-called (hypertensive cardiomyopathy) (Frohlich et al., 2011).

In our study, the aim was to assess presence of silent ischemia in type 2 diabetic and hypertensive patients with LVH in comparison to type 2 diabetic and hypertensive patients with normal LV geometry.

Regarding diabetes, all of our 60 patients were type 2 diabetic. Diabetic patients are at a greater risk for developing silent ischemia. Boras et al. (2010) concluded that SMI is more frequent in patients with diabetes (probably because of diabetic neuropathy). The prevalence of SMI is 10\%-20\% in diabetic patients versus $1 \%$ $4 \%$ in no diabetic patients. Exercise treadmill test (ETT) and ambulatory (Holter) monitoring are the most readily available and frequently used tests to identify SMI in clinical practice.

Bosone et al. (2017) evaluated the usefulness of Holter monitoring for the detection of silent myocardial ischemia (SMI) in elderly type 2 diabetic patients with hypertension and the possible relationship between SMI and cardiovascular autonomic neuropathy (CAN). They concluded that Holter monitoring was effective in detecting SMI in elderly type 2 diabetic patients with hypertension and might be used as initial screening test in such a population.

Nakao et al. (2015) did a study to investigate the usefulness of Holter monitoring to detect cardiac disease and predict future cardiovascular risk in asymptomatic diabetic patients. The study was done on 406 asymptomatic diabetic patients and he concluded that Holter monitoring may be a useful screening tool to detect cardiac disease and predict future cardiovascular risk in asymptomatic diabetic patients.

Left ventricular hypertrophy (LVH) has been long recognized as an independent risk factor for cardiovascular morbidity and mortality, including sudden cardiac death and dysrhythmia, heart failure, ventricular ischemia, and coronary heart disease (Diez et al., 2010 and Frohlich et al., 2011).

Sultana et al. (2010) assessed the association between LVH and increased risk of arrhythmias and mortality and was done on 500 hypertensive patients and was objected to investigate the prevalence of cardiac arrhythmias and LVH in systemic hypertension. It concluded that there was a significant association between hypertension and arrhythmias.

In our study, there was no significant difference between males and females in incidence of different types of $\mathrm{LV}$ patterns. That disagreed with findings of previous study by Hashem et al. (2015) who detected that concentric hypertrophy had higher incidence in males $(95 \%$ CI $0.23-0.61 \%, \quad 1.31-3.24 \%$ respectively). This disagreement may be due to a smaller number of patients included in our study compared to these studies.

In our study, diabetic hypertensive patients with LVH had more incidence of silent ischemia compared with patients with normal LV geometry. And there was a statistically significant relationship between the presence of LVH and positive holter findings for silent ischemia. 
Framingham Heart Study showed that increased left ventricular mass is a strong independent predictor of the risk of stroke, ischemic heart disease, and finally congestive heart failure through different pathways (Perrone-Filardi et al., 2017).

In the present study, the frequencies of different patterns of LV geometry were $50 \%$ the patients had normal geometry, $16.7 \%$ of them had mild concentric LVH, $23.3 \%$ of them had moderate concentric $\mathrm{LVH}$, and $10 \%$ of them had severe concentric LVH. We concluded that ambulatory ECG monitoring may have a use in the identification of those at greatest risk of cardiovascular complications and sudden death. That disagreed with Nassir (2018) who concluded that Holter monitoring was found to have no important role for the early diagnosis of arrhythmias or ischemia as a cause of complaint in patients with non-specific symptoms.

\section{LIMITATIONS}

Limited number of patients and not all patients did invasive coronary angiography and instead they did multislice CT coronary angiogram which is not the gold standard method

\section{CONCLUSION}

The prevalence of silent ischemia markedly increased amongst diabetic and hypertensive patients with LVH in comparison to those with normal left ventricular geometry. The incidence of silent ischemia increased with increased LVMI. Ambulatory ECG monitoring may have a use in the identification of those at greatest risk of cardiovascular complications and sudden death.

\section{REFERENCES}

1. Boras $\mathbf{J}$, Brkljačić $\mathbf{N}$, Ljubičić $\mathrm{A}$, and jubić $S$ (2010): Silent ischemia and diabetes mellitus. Diabetologia Croatica, 39(2):57-65.

2. Bosone D, Fogari R, Ramusino M, Ghiotto N, Guaschino E, Zoppi A, D'Angelo A and Costa A (2017): Ambulatory 24-h ECG Monitoring and Cardiovascular Autonomic Assessment for the Screening of Silent Myocardial Ischemia in Elderly Type 2 Diabetic Hypertensive Patients. Heart Vessels, 32(5):507-513.

3. Diez J and Frohlich $E$ (2010): A translational approach to hypertensive heart disease. Hypertension, 55(1):1-8.

4. Du Y, Plante E, Janicki J and Brower G (2010): Temporal evaluation of cardiac myocyte hypertrophy and hyperplasia in male rats secondary to chronic volume overload. Am J Pathol, 177(3):1155-63.

5. Frohlich E, González A and Diez J (2011): Hypertensive left ventricular hypertrophy risk: beyond adaptive cardiomyocytic hypertrophy. J Hypertens, 29(1):17-26.

6. Garg S, de Lemos J, Matulevicius S, Ayers C, Pandey A, Neeland I, Berry J, McColl $R$, Maroules C, Peshock $R$ and Drazner $M$ (2017): Association of Concentric Left Ventricular Hypertrophy with Subsequent Change in Left Ventricular End-Diastolic Volume: The Dallas Heart Study. Circ Heart Fail, 10(8):e003959-003969.

7. Hashem M, Kalashyan H, Choy J, Chiew S, Shawki A, Dawood A and Becher $H$ (2015): Left ventricular relative wall thickness versus left ventricular mass index in non-cardioembolic stroke patients. Medicine (Baltimore), 94(20): e872-876.

8. Jespersen L, Hvelplund A, Abildstrøm S, Pedersen F, Galatius S, Madsen J, Jørgensen E, Kelbæk $H$ and Prescott E (2012): Stable angina pectoris with no obstructive coronary artery disease is associated with increased risks of major adverse cardiovascular events. Eur Heart J, 33(6):734-44. 
9. Lang R, Badano L, Mor-Avi V, Afilalo J, Armstrong A, Ernande L, Flachskampf F, Foster E, Goldstein S, Kuznetsova T, Lancellotti P, Muraru D, Picard M, Rietzschel E, Rudski L, Spencer K, Tsang W and Voigt J (2015): Recommendations for Cardiac Chamber Quantification by Echocardiography in Adults: An Update from the American Society of Echocardiography and the European Association of Cardiovascular Imaging. Eur Heart J Cardiovasc Imaging, 16(3):233-70.

10. Lang $R$, Bierig $M$, Devereux $R$, Flachskampf F, Foster E, Pellikka P, Picard M, Roman M, Seward J, Shanewise J, Solomon S, Spencer K, Sutton M, Stewart W and Chamber Quantification Writing Group; American Society of Echocardiography's Guidelines and Standards Committee; European Association of Echocardiography (2005): Recommendations for chamber quantification: a report from the American Society of Echocardiography's Guidelines and Standards Committee and the Chamber Quantification Writing Group, developed in conjunction with the European Association of Echocardiography, a branch of the European Society of Cardiology. J Am Soc Echocardiogr, 18(12):1440-1463.

11. Nakao $Y$, Ueshima $K$, Nohara $R$, Mizunuma Y, Segawa I, Tanaka-Mizuno $S$, Yasuno S, Nakao K, Hiramori $K$ and Kihara Y (2015): Holter Monitoring for the Screening of Cardiac Disease in Diabetes Mellitus: The Non-Invasive Holter Monitoring Observation of New Cardiac Events in Diabetics Study. Diab Vasc Dis Res, 12(6):396-404.

12. Nassir S (2018): The Value of Holter Monitoring in the Assessment of NonSpecific Symptoms. Journal of Babylon University/Pure and Applied Sciences, 26 (3): $191-195$.

13. Perrone-Filardi $P$, Coca A, Galderisi $M$, Paolillo S, Alpendurada F, de Simone G, Donal E, Kahan T, Mancia G, Redon J, Schmieder R, Williams $B$ and AgabitiRosei E (2017): Noninvasive cardiovascular imaging for evaluating subclinical target organ damage in hypertensive patients: a consensus article from the European Association of Cardiovascular Imaging, the European Society of Cardiology Council on Hypertension and the European Society of Hypertension. J Hypertens, 35(9):1727-1741.

14. Rosendorff C, Lackland D, Allison M, Aronow W, Black $\mathrm{H}$, Blumenthal $\mathbf{R}$, Cannon C, de Lemos J, Elliott W, Findeiss L, Gersh B, Gore J, Levy D, Long J, O'Connor C, O'Gara P, Ogedegbe G, Oparil S, White W, American Heart Association, American College of Cardiology, and American Society of Hypertension (2015): Treatment of hypertension in patients with coronary artery disease: a scientific statement from the American Heart Association, American College of Cardiology, and American Society of Hypertension. Hypertension, 65(6):1372407.

15. Sara J, Widmer $R$, Matsuzawa $Y$, Lennon $R$, Lerman $L$ and Lerman A (2015): Prevalence of coronary microvascular dysfunction among patients with chest pain and no obstructive coronary artery disease. JACC Cardiovasc Interv, 8(11):1445-53.

16. Smith $\mathrm{S}$ Jr, Amsterdam E, Balady G, Bonow R, Fletcher G, Froelicher V, Heath G, Limacher M, Maddahi J, Pryor D, Redberg R, Roccella E, Ryan T, Smaha L and Wenger $N$ (2000): Prevention Conference V: beyond secondary prevention: identifying the high-risk patient for primary prevention: tests for silent and inducible ischemia: Writing Group II. Circulation, 101(1): E12-6.

17. Sultana R, Sultana N, Abdul Rashid Rasheed S, Ahmed M, Ishaq $M$ and Abdus Samad (2010): Cardiac Arrhythmias and Left Ventricular Hypertrophy in Systemic Hypertension. J Ayub Med Coll Abbottabad, 22(4):155-8. 


\section{تحديل العلاقة بين تضخم البطين الأيسر وحدوث قصور

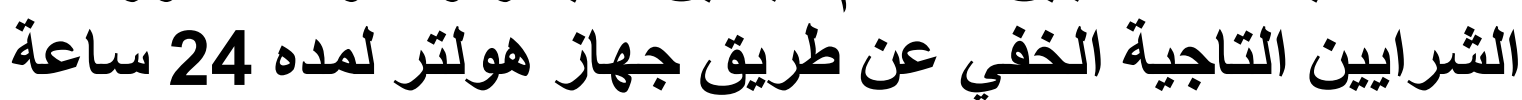

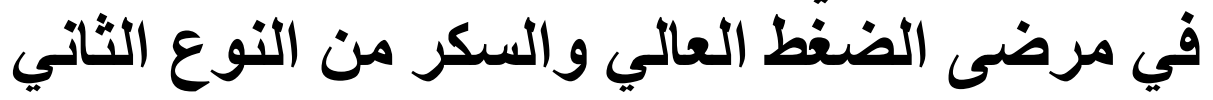
كريم الدين أحمد سعيد، مصطفى عطية السوساني، محمد سامي عبد السميع قسم القلب والأوعية الدموية، كلية الطب، جامعة الأزهر، القاهرة

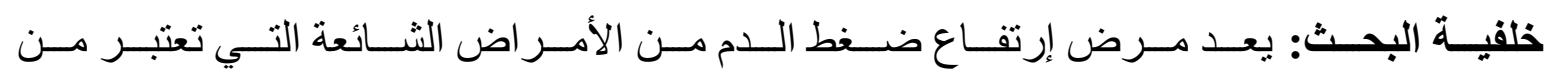

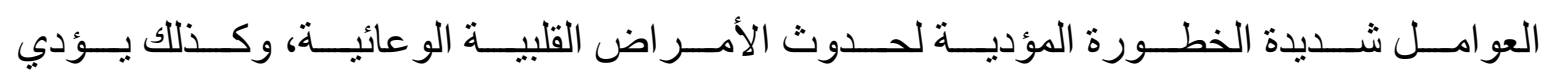

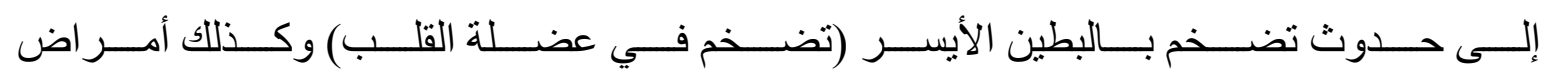

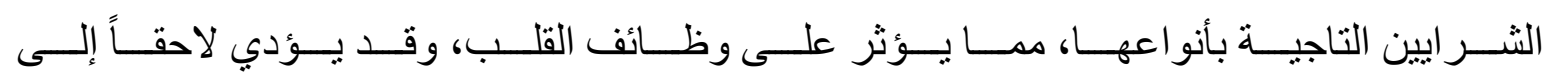

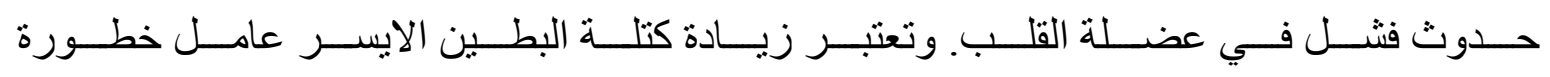

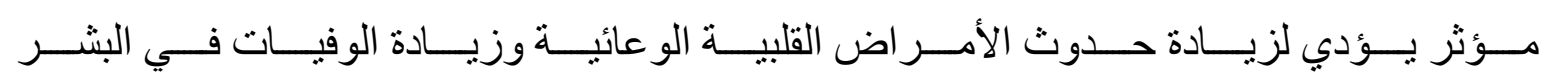

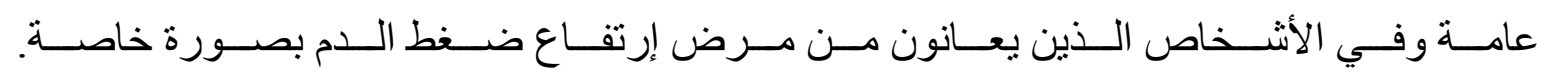

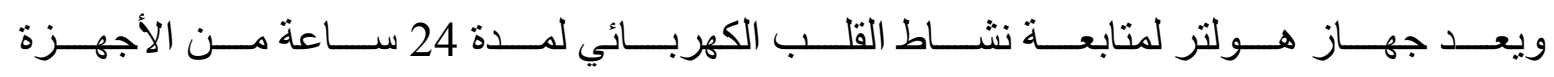

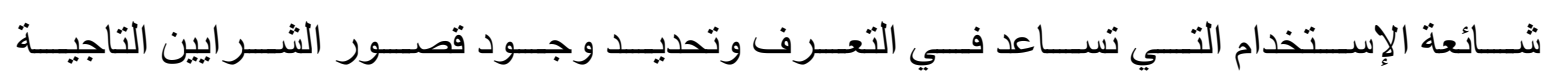
وله مميزات أكثر من رسم القلب بالمجهود في ذللك.

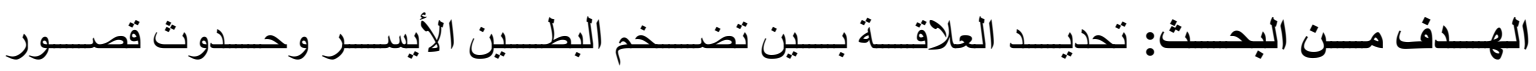

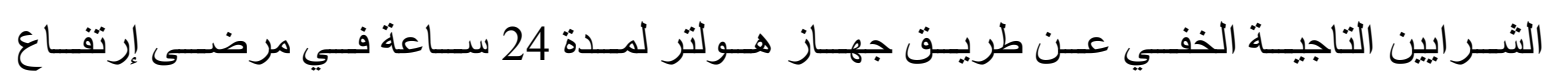
ضغط الدم والسكر من النوع الثاني.

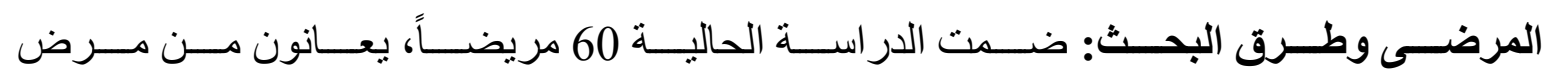

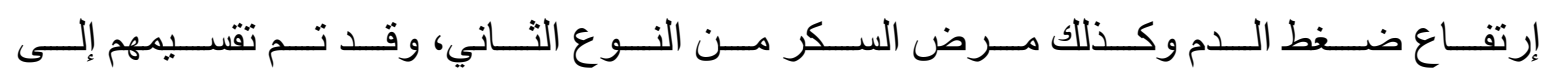

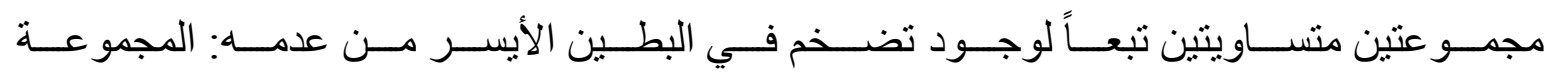

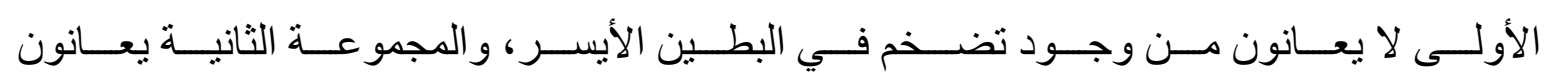
من وجود تضخم في البطين الأيسر.

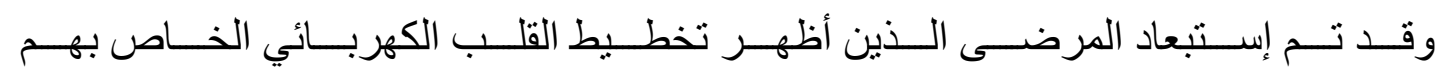

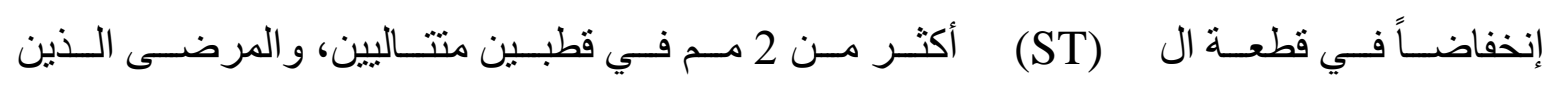

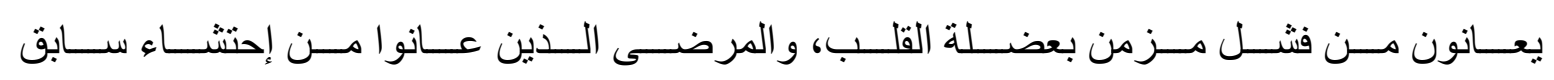




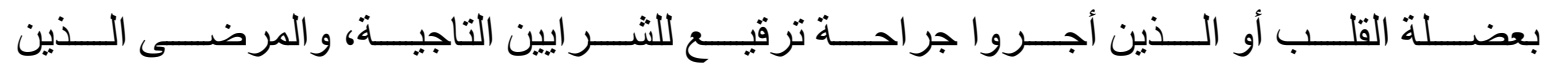

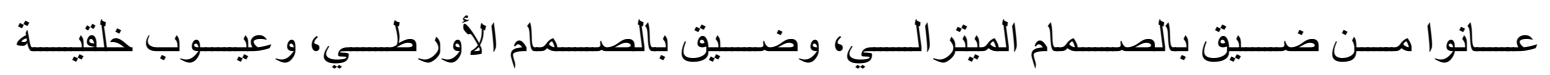

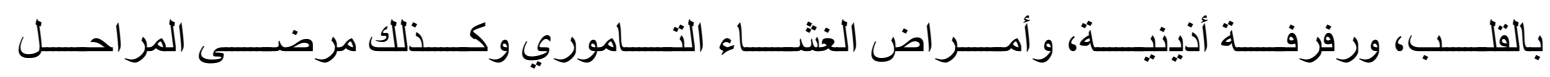
المتأخرة من أمر اض الكلى و أمر اض الكبد.

\section{وقد تم مناظرة جميع الحالات كالآتي:}

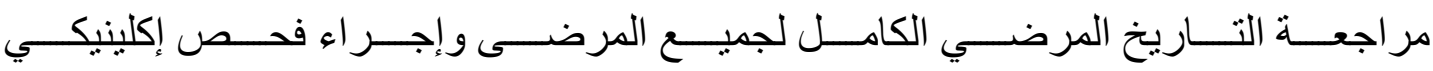
كامل لهم.

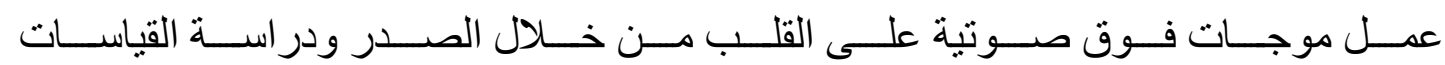

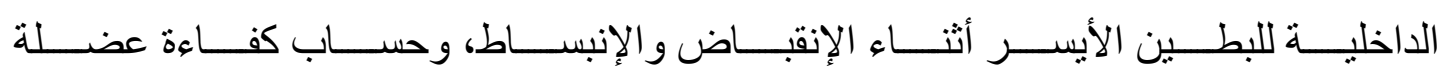

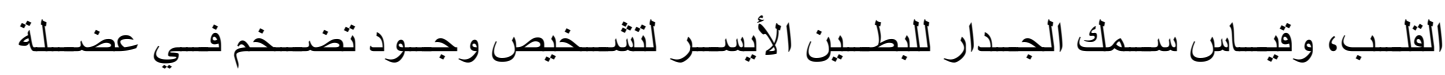
القلب من عدمه وكذلك لمعرفة درجة هذا التضخم.

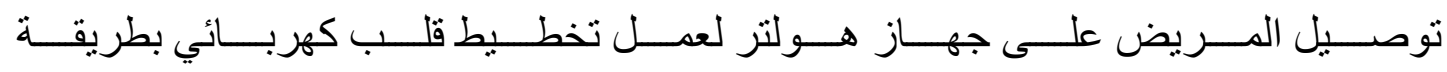
مستمرة ومتابعة نشاط القلب الكهربائي لمدة 24 ساعة.

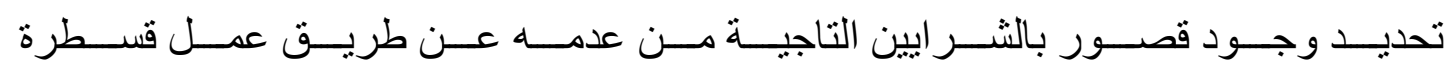

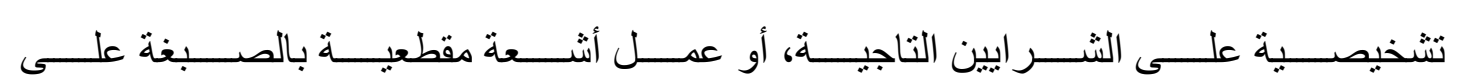
الثر ايين التاجية.

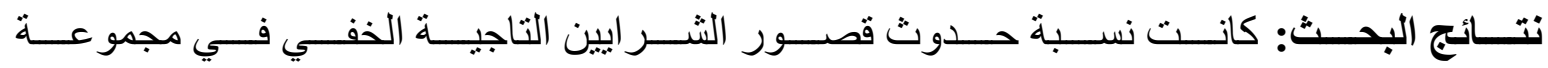

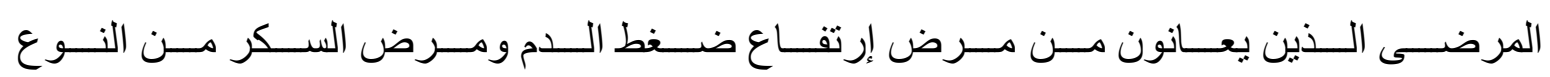

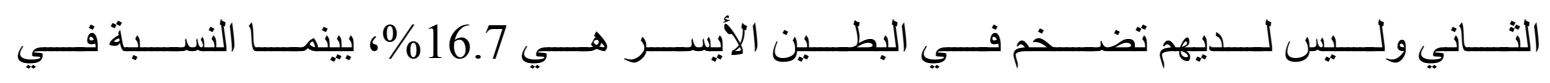

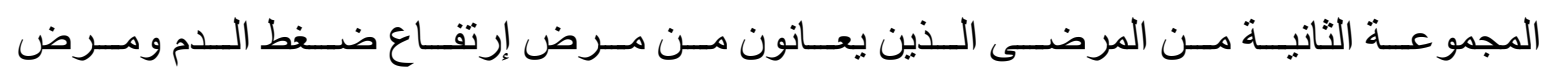

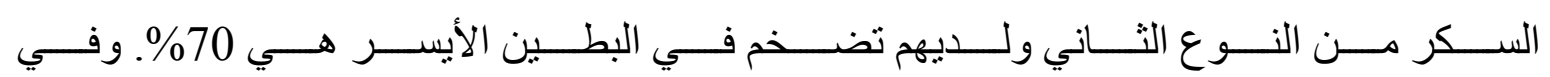

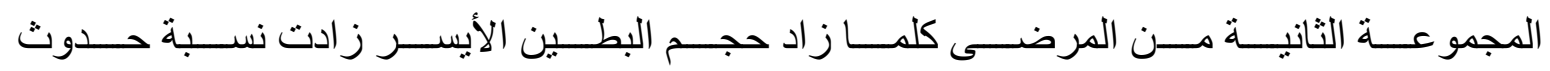

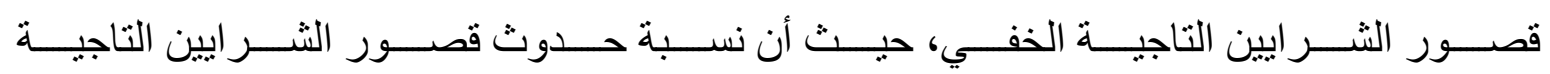

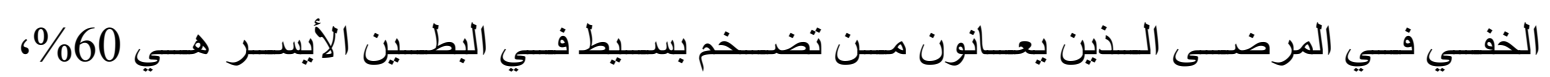

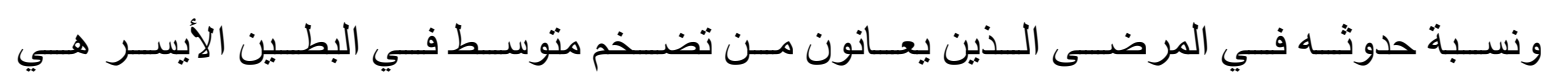




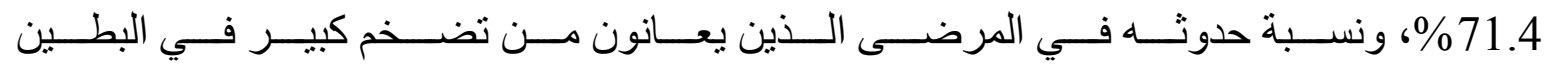

$$
\text { الأيسر هي \%3.3\% \% و.4. }
$$

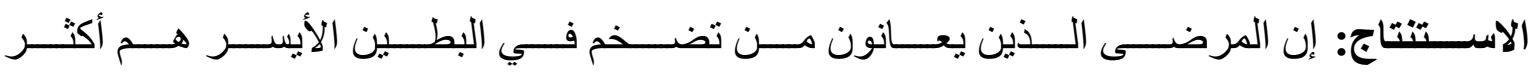

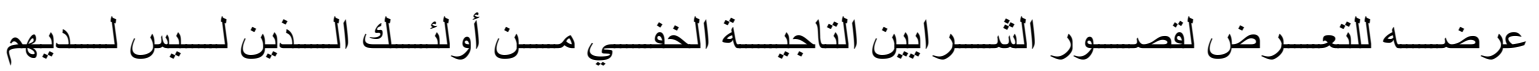

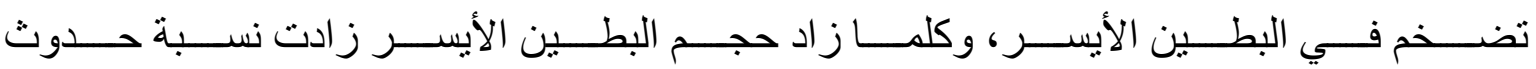

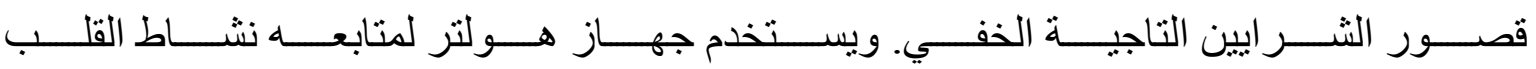

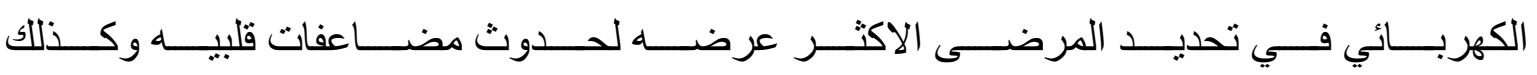
الأكثر عرضه لحدوث الوفاة المفاجئة. 